\title{
Correction to: Molecular quantification of spider preying on springtails in winter-spring fallow waterlogged paddy fields
}

\author{
Jiaqi Sun ${ }^{1} \cdot$ Shuai Pang ${ }^{1} \cdot$ Xueqin Wang $^{2,3} \cdot$ Guanghua Wang $^{2,3} \cdot$ Zengrong Zhu $^{3} \cdot$ Jiaan Cheng $^{3} \cdot$ Yaoyu Bai ${ }^{1}$
}

Published online: 30 January 2021

(c) The Japanese Society of Applied Entomology and Zoology 2021

\section{Correction to: Applied Entomology and Zoology https://doi.org/10.1007/s13355-020-00712-8}

In the original publication of the article, on the 3rd paragraph of results section, the following sentence "They were five dominant species in rice paddy ecosystem, including 187 P. subpiraticus, 74 (Sundevall) (Araneida: Linyphiidae); (Bösenberg and Strand) (Araneida: Linyphiidae) (Bösenberg and Strand) (Araneida: Clubionidae); (Karsch) (Araneida: Salticidae)." was published incorrectly.

The correct sentence should read as below,

They were five dominant species in rice paddy ecosystem, including 187 P. subpiraticus, 74 Erigonidium graminicolum (Sundevall) (Araneida: Linyphiidae), 52 Oedothorax insecticeps (Bösenberg and Strand) (Araneida: Erigonidae), 23
Clubiona japonicola (Bösenberg and Strand) (Araneida: Clubionidae) and 38 Marpissa magister (Karsch) (Araneida: Salticidae).

The original article has been corrected.

Publisher's Note Springer Nature remains neutral with regard to jurisdictional claims in published maps and institutional affiliations.

The original article can be found online at https://doi.org/10.1007/ s13355-020-00712-8.

Yaoyu Bai

yybai711@163.com

1 College of Plant Protection, Southwest University,

2 \# Tiansheng Road, Beibei 400715, Chongqing,

People's Republic of China

2 Institute of Plant Protection, Henan Academy of Agricultural Sciences, Zhengzhou 450002, China

3 Institute of Insect Sciences, Zhejiang University, Hangzhou 310058, China 